\title{
Improving the thermal stability of different types of xylan by acetylation
}

\section{Carvalho, Danila M.d.}

2019-09-15

Carvalho, D M D , Berglund, J , Marchand, C , Lindström, M E, Vilaplana, F \&

Sevastyanova, O 2019 , ' Improving the thermal stability of different types of xylan by acetylation ' , Carbohydrate Polymers , vol. 220 , pp. 132-140 . https://doi.org/10.1016/j.carbpol.2019.05.063

http://hdl.handle.net/10138/321589

https://doi.org/10.1016/j.carbpol.2019.05.063

cc_by_nc_nd

acceptedVersion

Downloaded from Helda, University of Helsinki institutional repository.

This is an electronic reprint of the original article.

This reprint may differ from the original in pagination and typographic detail.

Please cite the original version. 


\section{Improving the thermal stability of different types of xylan by acetylation}

Danila Morais de Carvalho ${ }^{\mathrm{a}, \mathrm{b}, \mathrm{c}^{*}}$, Jennie Berglund ${ }^{\mathrm{b}}$, Célia Marchand ${ }^{\mathrm{a}, \mathrm{d}}$, Mikael E. Lindströmª, ${ }^{\mathrm{a}, \mathrm{F}}$ Francisco Vilaplana $^{\mathrm{b}, \mathrm{e}}$, Olena Sevastyanova $\mathrm{a}^{\mathrm{a}, \mathrm{b}, *}$

${ }^{a}$ Department of Fibre and Polymer Technology, KTH, Royal Institute of Technology, SE-100 44 Stockholm, Sweden

${ }^{b}$ Wallenberg Wood Science Center, Department of Fibre and Polymer Technology, KTH, Royal Institute of Technology, SE-100 44 Stockholm, Sweden

'University of Helsinki, Department of Food and Nutrition, Faculty of Agriculture and Forestry, Finland, Agnes Sjöberginkatu 2, 00790 Helsinki, Finland

${ }^{\mathrm{d}}$ Grenoble INP-Pagora, Graduate School of Engineering in Paper, Print Media and Biomaterials, 38402 Grenoble, France

eDivision of Glycoscience, Department of Chemistry, KTH Royal Institute of Technology, AlbaNova University Center, SE-106 91 Stockholm, Sweden

*Corresponding authors at: Department of Fibre and Polymer Technology, KTH, Royal Institute of Technology, SE-100 44 Stockholm, Sweden.

E-mails: dmde@kth.se (D.M.de Carvalho), olena@kth.se (O. Sevastyanova).

\section{Abstract}

The impact of various degrees of acetylation on improving the thermal stability of xylan isolated from different botanical source has been studied; methylglucuronoxylan from birch and eucalyptus, arabinoglucuronoxylan from spruce and glucuronoarabinoxylan from sugarcane bagasse and straw. The lower molecular weight of non- acetylated methylglucuronoxylan (17.7-23.7 kDa) and arabinoglucuronoxylan $(16.8 \mathrm{kDa})$ meant that they were more soluble in water than glucuronoarabinoxylan (43.0-47.0 kDa). The temperature at the onset of degradation increased by $17-61^{\circ} \mathrm{C}$ and by $70-145^{\circ} \mathrm{C}$ for 
low and high acetylated xylans respectively, as a result of acetylation. A glass transition temperature in the range of $121-132^{\circ} \mathrm{C}$ was observed for the samples non-acetylated and acetylated at low degree of acetylation (0.0-0.6). The acetylation to higher degrees (1.4-1.8) increased the glass transition temperature of the samples to $188-206^{\circ} \mathrm{C}$. Acetylation proved to be an efficient method for functionalization of the xylan to increase the thermal stability.

Keywords: Acetylation, hardwood, molecular weight, softwood, sugarcane residues.

\section{Introduction}

The hemicelluloses are interesting and abundant biopolymers, which account for approximately one-third of dry the composition of wood and up to $50 \%$ of annual and perennial plants. Their structural diversity and their relatively easy functionalization places hemicelluloses in a strategic position as a substitute for traditional fossil-sources in industrial applications (Ebringerová, Hromádková, \& Heinze, 2005). From anatomical and structural points of view, hemicelluloses are key components in the cell wall, connecting cellulose and lignin (Belmokaddem, Pinel, Huber, Petit-Conil, \& Da Silva, 2011; Brandt, 2013).

Structurally, hemicelluloses can be classified as xylans, mannans, $\beta$-glucans and xyloglucans. Xylan is the most abundant hemicellulose in hardwoods and grasses, and is also present although less abundant in softwoods. It is a heteropolymer containing a $\beta-(1 \rightarrow 4)-\mathrm{D}$-xylopyranose backbone and is often substituted at positions 2 and/or 3 with sugar residues, such as 4- $O$-methyl- $\alpha$-D-glucopyranosyl acid and $\alpha$-L-arabinosyl (Ara). Native xylans are also partially $O$-acetylated at positions 2 and/or 3 and the degree of acetylation depends on the biomass type (Ebringerová, Hromádková, \& Heinze, 2005). Methylglucuronoxylan (GX), which has been identified in birch and eucalyptus xylans, contains substitutions of 4-O-methylgluconic acid (MeGlcA) exclusively at position 2 of the xylose units (Carvalho, 2015; Evtuguin, Tomás, Silva, \& Neto, 2003; Hansson \& Hartler, 1968; Teleman, Tenkanen, Jacobs, \& Dahlman, 2002). The interconnected position of the acetyl and MeGlcA side groups within the backbone of birch GX has recently been revealed (Martínez-Abad, Giummarela, Lawoko, \& Vilaplana, 2018). In the case of arabinoglucuronoxylan (AGX) 
and glucuronoarabinoxylan (GAX), $\alpha$-L-arabinosyl groups are present at position 3 , in addition to the MeGlcA at position 2. AGX and GAX differ with regard to the amount of MeGlcA and Ara residues on the xylan chain, and on the acetylation. On one hand, AGX, which is present in spruce xylan, is not acetylated and exhibits a higher degree of MeGlcA substitution than Ara (Escalante et al., 2012; McKee et al, 2016). The presence of regular motifs with distinct placement of the Ara and MeGlcA substituents in spruce AGX has recently been demonstrated (Martínez-Abad et al., 2017). On the other hand, GAX, usually observed in sugarcane bagasse and sugarcane straw xylan, can have single and double Ara substituents, has a lower ratio of MeGlcA than its the hardwood and softwood counterparts, and is lightly acetylated (Morais de Carvalho et al., 2017). Figure 1 shows assumed parts of the structures of GX, AGX and GAX.

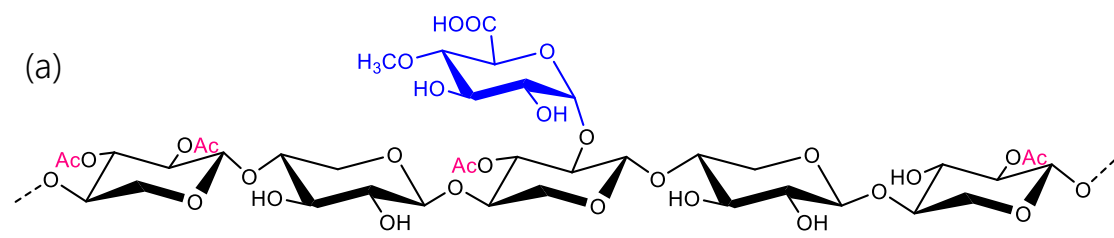

(b)

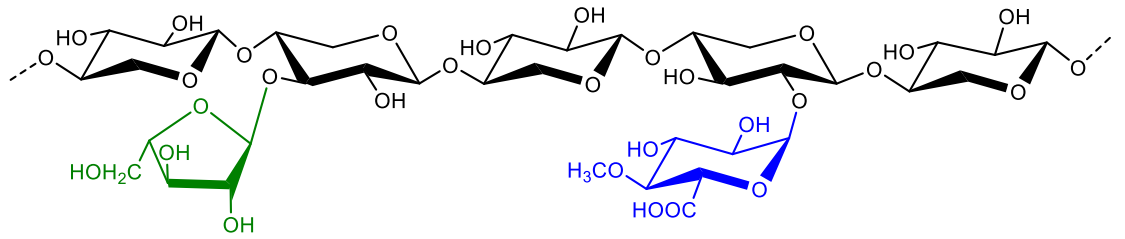

(c)
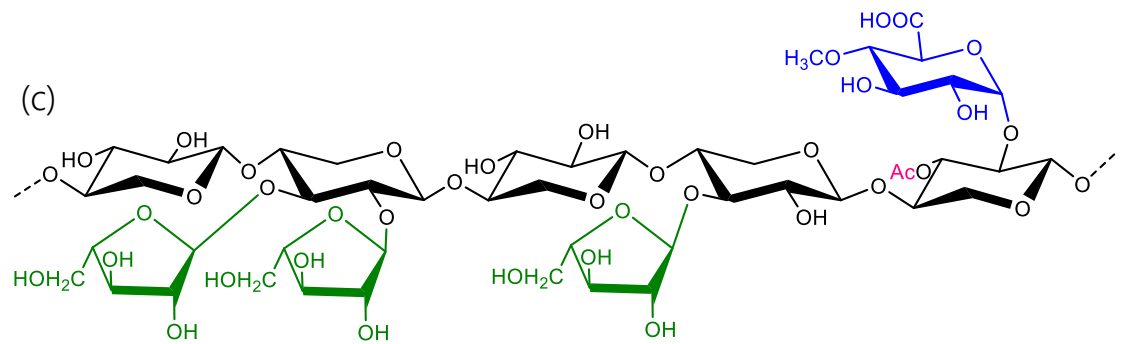

Figure 1. Schematic structure of (a) GX, (b) AGX and (c) GAX. Xylose units in the backbone are shown in black, MeGlcA residues in blue, Ara residues in green and acetyl groups (Ac) in pink.

The industrial application of xylan requires its isolation from lignocellulosic biomass and 
subsequent purification. The close association of hemicelluloses to cellulose and lignin, which play an important role in cell-wall arrangement, makes the efficient isolation of pure xylan samples difficult. Xylan isolation from lignocellulosic biomass usually involves three sequential and selective steps to remove extractives, lignin and cellulose (Evtuguin, Tomás, Silva, \& Neto, 2003; Hansson \& Hartler, 1968; Morais de Carvalho et al., 2017; Shatalov, Evtuguin, \& Neto, 1999; Sun, Sun, Sun, \& Su, 2004). Extractives are components that do not participate in the building of the cell-wall structure. Since there are no chemical bonds between extractives and hemicelluloses, their removal by solvent extraction is quite easy and efficient. Various delignification methods have been applied to remove lignin from extractives-free biomass (Evtuguin, Tomás, Silva, \& Neto, 2003; Morais de Carvalho et al., 2017; Shatalov, Evtuguin, \& Neto, 1999). Normally, harsher delignification conditions lead to a holocellulose (cellulose + hemicelluloses) of higher purity, but with possible polysaccharide degradation and sugar dissolution together with lignin. The efficiency of the separation depends on the nature of the chemical bonds between hemicelluloses and cellulose or lignin. Thus, the first step in xylan isolation is to find the necessary equilibrium between purity, integrity and yield. To increase the xylan yield, alkaline solutions are used to isolate alkali-soluble xylan (ASX) from the holocellulose. ASX is soluble in alkaline conditions at room temperature, while the cellulose remains in the insoluble fraction. The drawback of using an alkaline process is that it almost complete removes acetyl groups from the xylan structure (Chang \& Holtzapple, 2000). As a result, some xylan properties e.g., thermal stability, can be affected (Gröndahl, Teleman, \& Gatenholm, 2003). This undesirable reaction, however, can be compensated by subsequent acetylation of ASX.

Chemical modification to incorporate functionalities in the xylan structure is a useful strategy to change its properties. In cellulosic materials, such as xylan, hydroxyl groups are the most abundant and reactive sites for derivatization. The acetylation of xylan under controlled conditions leads to the substitution of hydroxyl groups by acetyl groups (Fig. 2). Each xylose unit contains two free hydroxyl groups available for derivatization on carbons 2 and 3 (Zhang, Zhang, Liu, \& Ren, 2016). Recently, the combination of dimethyl sulfoxide (DMSO) and 1-methylimidazole (or N-methylimidazole - NMI) has been reported to be an efficient medium for the acetylation of plant cell wall components, including xylan. In this system, the 
DMSO is combined with NMI, which accumulates the solvent and acylation catalyst functions and favors the following acetylation reaction (Lu \& Ralph, 2003; Zhang, Liu, Sun, Xie, \& Chen, 2012; Zhang, Zhang, Liu, \& Ren, 2016).

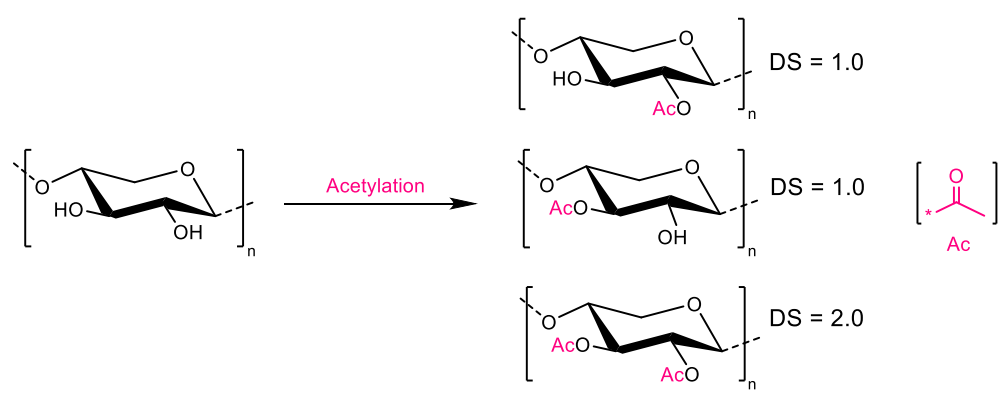

Figure 2. Simplified acetylation reaction. Acetyl groups are represented in pink.

The present study has evaluated the potential of acetylation for designing the xylan structure and changing the thermal and chemical properties of xylans from birch and eucalyptus (GX), spruce (AGX), sugarcane bagasse and sugarcane straw (GAX). Birch and spruce are important wood resources in temperate areas and eucalyptus is a valuable resource in tropical areas (Bertaud \& Holmbom, 2004; Gonzalez-García, Moreira, Feijoo, \& Murphy 2012; Teleman, Tenkanen, Jacobs, \& Dahlman, 2002). The sugarcane plant is an agricultural crop largely produced in tropical areas which generates a substantial amount of xylan-rich waste, i.e., bagasse and straw (Carvalho et al., 2015; Conab, 2015). Adding value to xylan can open the new applications for this biopolymer in consolidated and new industrial processes, in which the pulp and paper industry itself can also benefit. Xylan samples have been isolated from birch, eucalyptus, spruce, sugarcane bagasse and sugarcane straw using sodium chlorite delignification and potassium hydroxide extraction and subsequently acetylated using controlled conditions to achieve low and high degree of acetylation. The influence of the structural features of the xylans isolated from different biomass sources on the thermal and chemical properties has been assessed.

\section{Experimental}

\subsection{Materials and chemicals}


Five lignocellulosic biomasses were used for xylan isolation: birch, eucalyptus and spruce wood, sugarcane bagasse (SCB) and sugarcane straw (SCS). Birch and spruce chips were supplied by SCA Munksund, Piteå, Sweden. 7-year old eucalyptus chips were supplied by International Paper, Mogi Guaçu, SP, Brazil and 5-month old sugarcane bagasse and sugarcane straw were supplied by Center Sugarcane Experimentation (Oratórios, Minas Gerais State, Brazil). The biomasses were converted to sawdust (35 mesh) using a bench model Wiley mill and extracted with ethanol/toluene 1:2 (v/v) in a Soxhlet extractor (Sun, Sun, Sun, \& Su, 2004; Shatalov, Evtuguin, \& Neto, 1999). Extractives-free sawdust was dried at room temperature and stored in airtight plastic bags prior to use. The moisture content of the extractives-free sawdust was determined according to TAPPI T $264 \mathrm{~cm}-07$. Commercial xylan (CX) from birch (Sigma, Germany) was used as reference.

All chemicals were analytical grade, including ethanol 96\% (VWR, France), toluene 99.8\% (Sigma Aldrich, USA), glacial acetic acid (100\%) (VWR, France), sodium acetate 99\% (Merck, USA), sodium chlorite $80 \%$ (Alfa Aesar, Germany), acetone 99.5\% (VWR, France), polyester membrane (PES) (porosity $60 \mu \mathrm{m})$ (Monodur ${ }^{\circledR}$, Germany), potassium hydroxide $(\mathrm{KOH})$ lentils (Fisher Scientific, UK), barium hydroxide $\left(\mathrm{Ba}(\mathrm{OH})_{2}\right)$ (Sigma-Aldrich, Sweden), formic acid 98/100\% (VWR, England), methanol HPLC grade (Fisher Chemicals, UK), dimethyl sulfoxide 99.5\% (DMSO) (Sigma-Aldrich, France), 1methylimidazole $>99 \%$ (NMI) (Sigma-Aldrich, Germany), acetic anhydride (Aa) (Sigma-Aldrich, Germany), absolute ethanol (VWR, France) and chloroform (Fisher Scientific, UK).

\subsection{Xylan samples isolation}

\subsubsection{Biomass delignification}

Extractives-free sawdust was subjected to a three-step sodium chlorite $\left(\mathrm{NaClO}_{2}\right)$ delignification. For this, $10 \mathrm{~g}$ of extractives-free sawdust (dry basis) were suspended in $388 \mathrm{~mL}$ of water, $15 \mathrm{~mL}$ of glacial acetic acid, $72 \mathrm{~mL}$ of sodium acetate $30 \%(\mathrm{w} / \mathrm{v})$ and $55 \mathrm{~mL}$ of sodium chlorite $30 \%(\mathrm{w} / \mathrm{v})$ at $75^{\circ} \mathrm{C}$ with constant stirring. After $30 \mathrm{~min}$ intervals, $15 \mathrm{~mL}$ of glacial acetic acid, $72 \mathrm{~mL}$ of sodium acetate $30 \%(\mathrm{w} / \mathrm{v})$ and $55 \mathrm{~mL}$ of sodium chlorite $30 \%(\mathrm{w} / \mathrm{v})$ were added to the suspension, on a total of three occasions. After 
the delignification, the holocellulose was filtered using a polyester membrane, washed with $5 \mathrm{~L}$ of distilled water followed by $100 \mathrm{~mL}$ of acetone (Magaton, 2008). The holocellulose was dried at room temperature $\left(24^{\circ} \mathrm{C}\right)$ and stored in an air-tight container.

\subsubsection{Isolation of alkali-soluble xylan (ASX)}

$5 \mathrm{~g}$ of $\mathrm{NaClO}_{2}$-holocellulose (dry basis) was suspended in $140 \mathrm{~mL}$ of $\mathrm{KOH} 24 \%\left(\mathrm{w} / \mathrm{w}\right.$ ) at $24^{\circ} \mathrm{C}$ for $24 \mathrm{~h}$, under a nitrogen atmosphere with constant stirring. The suspension was then filtered through a polyester membrane and washed with $100 \mathrm{~mL}$ of distilled water.

The supernatant was added to $600 \mathrm{~mL}$ of ethanol at $\mathrm{pH} 3.5$ (adjusted with formic acid) and cooled overnight at $4{ }^{\circ} \mathrm{C}$ to precipitate the xylan. The precipitated xylan was recovered by centrifugation, washed 5 times with methanol and dried at room temperature $\left(24^{\circ} \mathrm{C}\right)$ (adapted from Hansson \& Hartler, 1968). The yield of xylan was estimated based on the xylose content of the extractives-free biomasses.

\subsubsection{Purification of ASX from spruce}

ASX from spruce obtained as described above was purified from mannan by slowly adding the ASX to water with constant stirring (1:6.6 w/v). After complete dispersion, 20\% (w/w) KOH was added dropwise until a final concentration of $10 \%(\mathrm{w} / \mathrm{w})$ was reached $(\mathrm{KOH}, 1: 13.2 \mathrm{w} / \mathrm{v})$. To promote the mannan precipitation, $5 \%(\mathrm{w} / \mathrm{w}) \mathrm{Ba}(\mathrm{OH})_{2}$ was added dropwise during $1 \mathrm{~h}$ in a ratio of $1: 2$ (xylan suspension in $10 \%$ $\left.\mathrm{KOH}: 5 \% \mathrm{Ba}(\mathrm{OH})_{2}\right)$. The suspension was kept stirred for an additional $1 \mathrm{~h}$ and kept without stirring for $3 \mathrm{~h}$. The precipitate was separated by centrifugation and the supernatant was added to ethanol supplemented with glacial acetic acid in a ratio of 1:4:0.4 v/v/v (supernatant, ethanol, glacial acetic acid). The suspension was cooled at $4^{\circ} \mathrm{C}$ overnight for xylan precipitation. The xylan was recovered by centrifugation and washed with 96\% ethanol (Escalante et al., 2012; Timell, 1961). Four steps of purification were necessary to obtain xylan samples with a purity greater than $90 \%$.

\subsection{Controlled acetylation of xylan at low and high degrees of acetylation}


$440 \mathrm{mg}$ of xylan (dry basis) were suspended in $40 \mathrm{~mL} \mathrm{DMSO}$ and $20 \mathrm{~mL} \mathrm{NMI}$ at $100^{\circ} \mathrm{C}$ for $5 \mathrm{~h}$ using a dark flask under a nitrogen atmosphere with constant stirring. The temperature was lowered to room temperature and the suspension was kept under constant stirring for a further $19 \mathrm{~h}$ (reaching a total of $24 \mathrm{~h}$ for xylan solubilization). Acetylation was performed with acetic anhydride (Aa) as the esterifying agent, the amount of Aa used being calculated assuming that $440 \mathrm{mg}$ of xylan contains $6.68 \mathrm{mmol}$ hydroxyl groups (Zhang, Zhang, Liu, \& Ren, 2016). Aa was added dropwise to the mixture for mild (0.9-1.9:1 Aa/hydroxyl groups in xylan - mol/mol) and moderate $(25: 1 \mathrm{Aa} / \mathrm{hydroxyl}$ groups in xylan - mol/mol) acetylation and the reaction was allowed to continue for $24 \mathrm{~h}$ at room temperature under constant stirring. The reaction was quenched in an ice bath by the addition of $200 \mathrm{~mL}$ cold MilliQ- $\mathrm{H}_{2} \mathrm{O}$. The acetylated xylan was thereafter precipitated by $800 \mathrm{~mL}$ cold ethanol and cooled at $4^{\circ} \mathrm{C}$ overnight. The suspension was centrifuged and the xylan was recovered, washed with ethanol/water solution ( $80 \%$ ethanol) and then freeze-dried (adapted from Gröndahl, Teleman, \& Gatenholm, 2003 and Zhang, Zhang, Liu, \& Ren, 2016).

The different degrees of acetylation in xylan samples were obtained using different dosages of Aa. To achieve a low degree of acetylation, the xylan samples were acetylated under mild conditions, i.e., using 1.9:1 Aa/ hydroxyl groups (mol/mol) $(1.2 \mathrm{~mL} \mathrm{Aa})$ for xylan from birch, eucalyptus, SCB and SCS and using 0.9:1 Aa/hydroxyl groups $(\mathrm{mol} / \mathrm{mol}) \quad(0.6 \mathrm{~mL} \mathrm{Aa})$ for xylan from spruce. To reach a high degree of acetylation, all the xylan samples were acetylated under moderate conditions, i.e., using 25:1 Aa/hydroxyl groups (mol/mol) in xylan (16 mL Aa). Only the commercial birch achieved the high degree of acetylation after the moderate acetylation in one-step. Thus, to obtain the high degree of acetylation for the rest of the samples, the dry xylan samples from birch, eucalyptus, spruce, SCB and SCS obtained after moderate acetylation were subjected to an additional (second) acetylation step under exactly same conditions (Morais de Carvalho et al., 2019).

\subsection{Thermal and chemical characterization of xylan structure}

The sugar composition of the xylan samples was assessed by acid methanolysis (Appeldoorn, Kabel, Van Eylen, Gruppen, \& Schols, 2010; Bertaud, Sundber, \& Holmbom, 2002). 1 mg freeze-dried 
sample was suspended for $5 \mathrm{~h}$ in $1 \mathrm{~mL}$ of $2 \mathrm{~mol} \mathrm{~L}^{-1}$ hydrochloric acid $(\mathrm{HCl})$ in dry methanol at $100^{\circ} \mathrm{C}$. The suspension was then neutralized with pyridine and dried under an atmosphere of inert gas. Thereafter, $1 \mathrm{~mL}$ of $2 \mathrm{~mol} \mathrm{~L}^{-1}$ trifluoroacetic acid (TFA) was added to the sample and the hydrolysis was performed at $120^{\circ} \mathrm{C}$ for $1 \mathrm{~h}$. The suspension was again dried under an atmosphere of inert gas and dissolved in $1 \mathrm{~mL}$ of water $\left(\mathrm{H}_{2} \mathrm{O}\right)$. The hydrolysates were analyzed by high performance anion-exchange chromatography with pulsed amperometric detection (HPAEC-PAD) using an ICS-3000 system (Dionex) equipped with a CarboPac PA1 column (4 × $250 \mathrm{~mm}$, Dionex) as previously described (Morais de Carvalho et al., 2017).

The acetyl content in the acetylated xylans was assessed by saponification. A sample of approximately $7 \mathrm{mg}$ acetylated xylan was placed in a $2 \mathrm{~mL}$ Eppendorf tube and suspended in $300 \mu \mathrm{L}$ water, $1.2 \mathrm{~mL} 0.8 \mathrm{~mol} \mathrm{~L}^{-1}$ sodium hydroxide $(\mathrm{NaOH})$ and $10 \mu \mathrm{L} 1 \mathrm{~mol} \mathrm{~L}^{-1}$ propionic acid (internal standard) and agitated at $60^{\circ} \mathrm{C}$ overnight. After complete xylan dissolution, the solution was neutralized using $37 \% \mathrm{HCl}$ and filtered through chromacol $(0.45 \mu \mathrm{m})$ filters to HPLC vials. The samples were then analyzed by highperformance liquid chromatography (HPLC) (Bi, Berglund, Vilaplana, McKee, \& Henriksson, 2016).

The degree of acetylation $\left(\mathrm{DS}_{\mathrm{Ac}}\right)$ was determined from the acetyl content in the xylan samples according to (Xu et al., 2010):

$$
D S_{A c}=\frac{132 \times \% \text { acetyl }}{\left(M_{\text {acetyl }} \times 100\right)-\left(M_{\text {acetyl }}-1\right) \times \% \text { acetyl }}
$$

where: \% acetyl is the acetyl content determined by HPLC and $M_{\text {acetyl }}$ is the molecular weight of acetyl groups $(43 \mathrm{~g} / \mathrm{mol})$.

The molar mass distributions of the non-acetylated xylan samples were determined using a sizeexclusion chromatograph (SEC) (SECcurity 1260, Polymer Standard Services, Mainz, Germany) coupled in series with a multiple-angle laser light scattering detector (MALLS; BIC-MwA7000, Brookhaven Instrument Corp., New York) and a refractive index detector (SECcurity 1260, Polymer Standard Services, Mainz, Germany). A $4 \mathrm{mg} / \mathrm{mL}$ xylan solution was prepared by dissolving the xylan samples directly in the 
SEC eluent $(0.5 \% \mathrm{LiBr} / \mathrm{DMSO})$ for $16 \mathrm{~h}$ at $60^{\circ} \mathrm{C}$ under constant stirring. Next, the solution was filtered through $0.45 \mu \mathrm{m}$ PTFE syringe filters and analyzed by SEC. The samples were separated by GRAM columns (Polymer Standard Services, Mainz, Germany) where a PreColumn (50 x 8 mm, $10 \mu \mathrm{m}$ particle size), a $100 \AA$ column, and a $10000 \AA$ column $(300$ x 8 mm, $10 \mu \mathrm{m}$ particle size $)$ were connected in series. The flow was $0.5 \mathrm{ml} / \mathrm{min}$, the column oven was at $60{ }^{\circ} \mathrm{C}$, and the RI-detector at $40{ }^{\circ} \mathrm{C}$. Standard calibration with 9 pullulan standards with a Mp ranging between 342 and 708000 Da (Polymer Standard Services, Mainz, Germany) was used for standard calibration determining the apparent molecular weight of the samples. The analysis was performed in duplicates.

The chemical structure based on functional groups was assessed using Fourier transform infrared (FTIR) spectroscopy using a Perkin-Elmer Spectrum 100 FTIR spectrometer equipped with a single reflection (ATR: attenuated total reflection) (Golden gate from Graseby Specac LTD, Kent, England). The spectra of dry samples were collected in the of $4000-600 \mathrm{~cm}^{-1}$ range wavelength using 16 scans at a resolution of $4 \mathrm{~cm}^{-1}$ at intervals of $1 \mathrm{~cm}^{-1}$ at room temperature. The curves obtained were baseline corrected and normalized.

The solubility of xylans in water, dimethyl sulfoxide (DMSO) and chloroform $\left(\mathrm{CHCl}_{3}\right)$ was assessed by adding the solvent to xylan samples to a final concentration of $5 \mathrm{mg} / \mathrm{mL}$ and stirring at room temperature and $80^{\circ} \mathrm{C}$ (water and DMSO only) for $24 \mathrm{~h}$ (Gröndahl, Teleman, \& Gatenholm, 2003). The solubility was assessed visually.

The thermal properties were evaluated by thermogravimetric analysis and differential scanning calorimetry. For this, 2-8 mg xylan samples were subjected to thermogravimetric analysis (TGA) using a Mettler Toledo TGA/DSC 1 instrument coupled with a STAR ${ }^{\mathrm{e}}$ System. The thermal stability was measured in a heating from 25 to $600^{\circ} \mathrm{C}$ with a heating rate of $10^{\circ} \mathrm{C} / \mathrm{min}$ in nitrogen. $2-5 \mathrm{mg}$ xylan samples were subjected to differential scanning calorimetry (DSC) using a Mettler Toledo DSC 1 instrument coupled with a STAR ${ }^{\mathrm{e}}$ System. Samples were scanned in two subsequent heating processes. The first heating (from 25 to $105^{\circ} \mathrm{C}$ ) was performed for moisture removal. The sample was then cooled to $25^{\circ} \mathrm{C}$ and heated again to $400^{\circ} \mathrm{C}$. Heating and cooling were performed at a heating rate of $10^{\circ} \mathrm{C} / \mathrm{min}$ in nitrogen. The second heating 
scan was used for glass transition $\left(\mathrm{T}_{\mathrm{g}}\right)$ determination.

\section{Results and Discussion}

\subsection{Assessment of the xylan isolation processes and the chemical composition of the xylan samples}

The total yield after the isolation of ASX samples was calculated considering from the yield of $\mathrm{NaClO}_{2}$ - and $\mathrm{KOH}$-processes and the xylan content of the ASX samples. The results were reported as the xylan content on an extractives-free basis. For birch and eucalyptus, the sugars used in estimation of the xylan content were xylose and 4-O-methylglucuronic acid (MeGlcA). For spruce, sugarcane bagasse and sugarcane straw, the arabinose was considered together with the xylose and MeGlcA in the estimation. About $84.7 \%, 78.8 \%$ and $58.1 \%$ of xylan was respectively isolated from birch, eucalyptus and spruce biomasses (Table 1). The low yield from spruce can be explained by the extensive xylan loss observed during the $\mathrm{Ba}(\mathrm{OH})_{2}$ purification. The xylan content of contamination extracted by $\mathrm{Ba}(\mathrm{OH})_{2}$ purification varied between 13.8 and $34.7 \%$.

Table 1. Yield of xylan isolation and purity of the xylan samples

\begin{tabular}{ccccccc}
\hline \multirow{2}{*}{ Parameters } & Commercial & \multicolumn{5}{c}{ ASX } \\
\cline { 3 - 6 } & xylan & Birch & Eucalyptus & Spruce & SCB & SCS \\
\hline Yield*, \% & - & 84.7 & 78.8 & 58.1 & 70.0 & 62.4 \\
\hline Purity**, \% & 96.0 & 90.2 & 80.8 & 92.6 & 93.3 & 92.5 \\
\hline
\end{tabular}

*[Based on sugars present in xylan structure in the different biomasses, dry basis].

$* *$ [Obtained from the results of sugar analysis].

The sugar analysis confirmed the presence of methylglucuronoxylan in birch and eucalyptus, arabinoglucuronoxylan in spruce and glucuronoarabinoxylan in sugarcane bagasse and straw (Fig. 3). The alkaline process gave samples with a lower purity, than that of the commercial xylan (CX) from birch, especially the ASX from eucalyptus (Table 1). However, in addition to xylose and MeGlcA in the eucalyptus xylan, a previous study using DMSO-soluble xylan from the same eucalyptus sample was investigated by glycosidic linkage analysis which showed the presence of terminal galactosyl units linked to a certain 
number of MeGlcA units (Carvalho, 2015). The presence of other polysaccharide fragments linked to eucalyptus xylan by MeGlcA, such as glucan and rhamnoarabinogalactan, has also been observed elsewhere (Evtuguin, Tomás, Silva, \& Neto, 2003). The simplification assumed in the present study for the structure of eucalyptus xylan has probably led to an underestimation of the xylan content. But, since the xylan samples were not investigated by glycosidic linkage analysis, the correct amount of other monosaccharides (e.g., galactose) in the xylan structure was not determined and was, consequently, not included in the estimation of the purity of the xylan samples.

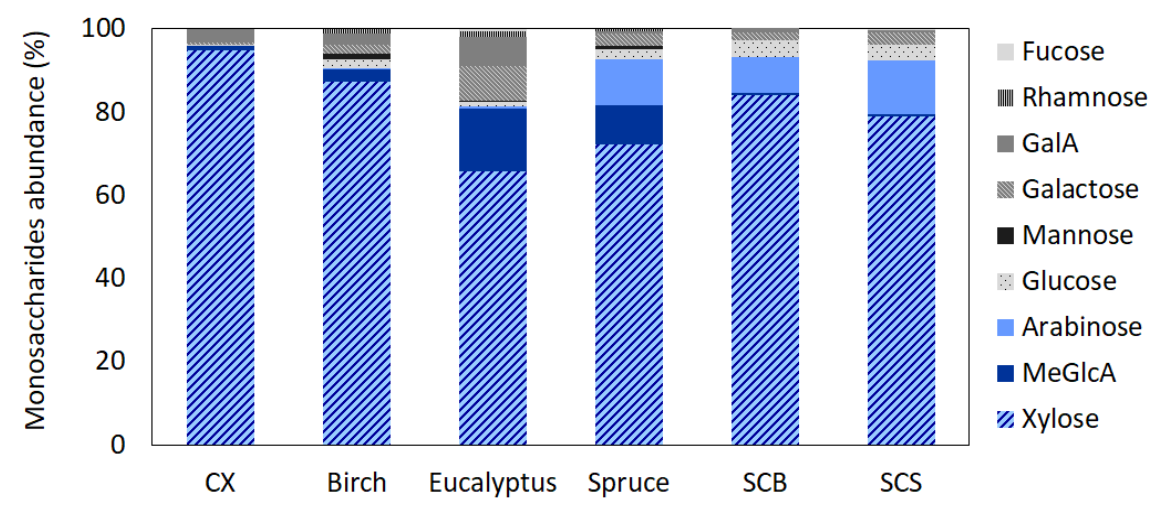

Figure 3. Sugar composition of commercial xylan (CX) from birch and ASX xylan samples from birch, eucalyptus, spruce, sugarcane bagasse and sugarcane straw.

\subsection{Impact of xylan reactivity on the acetylation process}

The esterification reaction can be assessed with reference to two main parameters: solubility/dispersibility and reactivity. The solubility/dispersibility is the ability of xylan chains to open up in the reaction medium and expose the hydroxyl groups for acetylation reaction, but the ease and speed with which this reaction occurs depends on the reactivity of both the xylan and the esterifying agent.

To understand the dynamics of solubility/dispersibility it is important to understand the design of the acetylation method. The xylan samples were subjected to acetylation with acetic acid (Aa) as the esterifying agent in DMSO/NMI as reaction medium. Zhang, Zhang, Liu, \& Ren, (2016) acetylated 
commercial xylan isolated from sugarcane bagasse by first dispersing xylans in DMSO/NMI $\left(100^{\circ} \mathrm{C}\right.$ for one hour) and then adding Aa at Aa/xylan molar ratio in the range of 0.5:1 to 8:1. Such conditions did not, however, work well for our ASX samples. Preliminary tests showed that this was too short time to achieve a good dispersion of the ASX in the DMSO/NMI medium, and this limited the efficiency of the acetylation reaction. Different combinations of time and temperature were tested and monitored and the most suitable combination was found to be $5 \mathrm{~h}$ at $100^{\circ} \mathrm{C}$ followed by $19 \mathrm{~h}$ at room temperature. Comparing the conditions chosen for our ASX with those used by Zhang, Zhang, Liu, \& Ren, (2016) for commercial xylan, it was clear that the solubility/dispersibility of ASX samples was poorer.

The xylan reactivity affects the acetylation, such as the molar ratio of reagents, the degree of acetylation and the percentage gain in weight, as suggested by Zhang, Zhang, Liu, \& Ren, (2016). Commercial xylan from birch was more reactive than ASX, requiring only a single acetylation under moderate conditions to achieve high degree of acetylation (1.59) (Table 2). Surprisingly, except in the case of the spruce xylan, an increase in the amount of Aa did not increase the acetylation with only a single acetylation step, probably because of the low reactivity of the ASX sample and the presence of impurities, e.g., residual lignin. For ASX samples, a high degree of acetylation (1.35-1.76) was achieved only in two steps under moderate condition. The highest Aa/xylan molar ratio required in this study was 0.9:1 - 25:1 compared to the value of 0.5:1 - 8:1, reported in the literature (Zhang, Zhang, Liu, \& Ren, 2016). A high acetylation yield was only observed under harsh acetylation conditions, indicating that the ASX in this study was less reactive than commercial xylan (Table 2).

Among the various ASX, a spruce xylan, was the most reactive, so that less Aa was required to produce xylan with a low degree of acetylation. The high reactivity of the spruce ASX may be a result of the intensive purification process to which this sample was subjected during mannan decontamination, where less reactive and insoluble polysaccharide fragments were probably eliminated together with the mannan. It is also possible that the repetition of the purification steps gave the xylan structure a more reactive conformation. The methodology used for purification can apparently affect the reactivity of the ASX samples, and this requires further investigation. 
Table 2. Acetylation parameters (Aa/xylan molar ratio and acetic anhydride volume) and results of acetylation.

\begin{tabular}{|c|c|c|c|c|c|c|}
\hline Sample & $\begin{array}{l}\text { Acetylation } \\
\text { condition* }\end{array}$ & $\begin{array}{c}\text { Aa/xylan, } \\
\mathrm{mol} / \mathrm{mol}\end{array}$ & $\begin{array}{c}\text { Acetic anhydride, } \\
\mathrm{mL}\end{array}$ & $\begin{array}{c}\text { Acetyl } \\
\text { groups, \% }\end{array}$ & $\mathrm{DS}_{\mathrm{Ac}^{*}}{ }^{* *}$ & $\begin{array}{c}\text { Acetylation } \\
\text { yield, } \%\end{array}$ \\
\hline \multirow{2}{*}{$\begin{array}{c}\text { Commercial } \\
\text { Birch }\end{array}$} & - & - & - & $1.4 \pm 0.1$ & $0.04 \pm 0.00$ & - \\
\hline & Mod. $(1 \times)$ & $25: 1$ & 16 & $34.4 \pm 0.5$ & $1.59 \pm 0.04$ & 121.0 \\
\hline \multirow{3}{*}{ Birch } & Mild & $1.9: 1$ & 1.2 & $12.2 \pm 0.6$ & $0.42 \pm 0.02$ & 85.9 \\
\hline & Mod. $(1 \times)$ & $25: 1$ & 16 & $16.4 \pm 1.5$ & $0.60 \pm 0.07$ & 93.6 \\
\hline & Mod. $(2 \times)$ & $25: 1$ & 16 & $30.8 \pm 0.0$ & $1.35 \pm 0.00$ & 116.9 \\
\hline \multirow{3}{*}{ Eucalyptus } & Mild & $1.9: 1$ & 1.2 & $2.8 \pm 0.1$ & $0.09 \pm 0.00$ & 77.7 \\
\hline & Mod. $(1 \times)$ & $25: 1$ & 16 & $3.9 \pm 0.2$ & $0.13 \pm 0.01$ & 81.4 \\
\hline & Mod. $(2 \times)$ & $25: 1$ & 16 & $32.8 \pm 0.4$ & $1.48 \pm 0.03$ & 113.2 \\
\hline \multirow{3}{*}{ Spruce } & Mild & $0.9: 1$ & 0.6 & $16.1 \pm 1.0$ & $0.59 \pm 0.04$ & 91.3 \\
\hline & Mod. $(1 \times)$ & $25: 1$ & 16 & $25.1 \pm 0.5$ & $1.02 \pm 0.03$ & 98.2 \\
\hline & Mod. $(2 \times)$ & $25: 1$ & 16 & $32.0 \pm 0.3$ & $1.43 \pm 0.02$ & 70.8 \\
\hline \multirow{3}{*}{$\begin{array}{l}\text { Sugarcane } \\
\text { bagasse }\end{array}$} & Mild & $1.9: 1$ & 1.2 & $7.5 \pm 0.2$ & $0.25 \pm 0.01$ & 70.3 \\
\hline & Mod. $(1 \times)$ & $25: 1$ & 16 & $7.5 \pm 0.4$ & $0.25 \pm 0.02$ & 77.6 \\
\hline & Mod. $(2 \times)$ & $25: 1$ & 16 & $36.7 \pm 0.7$ & $1.76 \pm 0.05$ & 130.9 \\
\hline \multirow{3}{*}{$\begin{array}{l}\text { Sugarcane } \\
\text { straw }\end{array}$} & Mild & $1.9: 1$ & 1.2 & $4.3 \pm 0.4$ & $0.14 \pm 0.01$ & 73.1 \\
\hline & Mod. $(1 \times)$ & $25: 1$ & 16 & $5.2 \pm 0.1$ & $0.17 \pm 0.00$ & 76.3 \\
\hline & Mod. $(2 \times)$ & $25: 1$ & 16 & $36.5 \pm 0.6$ & $1.74 \pm 0.05$ & 136.8 \\
\hline
\end{tabular}

*[Mild: acetylation performed under mild conditions; Mod. $(1 \times)$ : acetylation performed under moderate conditions in only one step; and Mod. $(2 \times)$ : acetylation performed under moderate conditions in two sequential steps. See detailed description in section 2.3].

**[Degree of substitution with acetyl groups in xylan structure].

\subsection{Thermal and chemical properties of non-acetylated and acetylated xylan structures}

\subsubsection{Changes in chemical structure of xylan samples as a result of acetylation}

The acetylation of the xylan samples was confirmed by FTIR spectra and the results for SCB are presented in Figure 4a. FTIR spectra for the other xylan samples were similar to that observed for the SCB sample and they are presented in the Supplementary Data (Fig. S1).

The presence of xylan in the commercial and ASX samples was confirmed by the typical bands for polysaccharides observed at 3376, 2952, 1620, 1466-1428, 1037 and 897-894 $\mathrm{cm}^{-1}$ (Chaikumpollert, Methacanon, \& Suchiva, 2004; Drobniak \& Mastalerz, 2006; Gupta, Madan, \& Bansal, 1987; Kačuráková, Belton, Wilson, Hirsch, \& Ebringerová, 1998; Sun, Sun, Sun, \& Su, 2004). The presence of hydroxyl groups on the xylan structure was confirmed by a typical broad band at $3376 \mathrm{~cm}^{-1}$, and the interaction of hydroxyl groups with water through hydrogen bonding was observed at $1620 \mathrm{~cm}^{-1}$ (Kačuráková, Belton, Wilson, 
Hirsch, \& Ebringerová, 1998). The acetylation of the xylan was proven by the appearance of a band at 1740 $\mathrm{cm}^{-1}$ and also confirmed by the change in intensity or the disappearance of bands at 3376, 2952, 1620, 1368 and $1235 \mathrm{~cm}^{-1}$. The intensity of the signal at $1740 \mathrm{~cm}^{-1}(\mathrm{C}=\mathrm{O}$ stretching $)$ increased with increasing degree of acetylation (Bian, Peng, Xu, Sun, \& Kennedy, 2010), and the substitution of hydroxyl groups by acetyl groups increased the intensity of other bands such as those related to $\mathrm{C}_{-} \mathrm{CH}_{3}$ stretching $\left(1368 \mathrm{~cm}^{-1}\right)$ and $\mathrm{C}$ O stretching $\left(1235 \mathrm{~cm}^{-1}\right)$ (Belmokaddem, Pinel, Huber, Petit-Conil, \& Da Silva, 2011). Although the samples might contain traces of lignin bonded to the xylan, the bands due to this (around $1510 \mathrm{~cm}^{-1}$ ) were not observed.
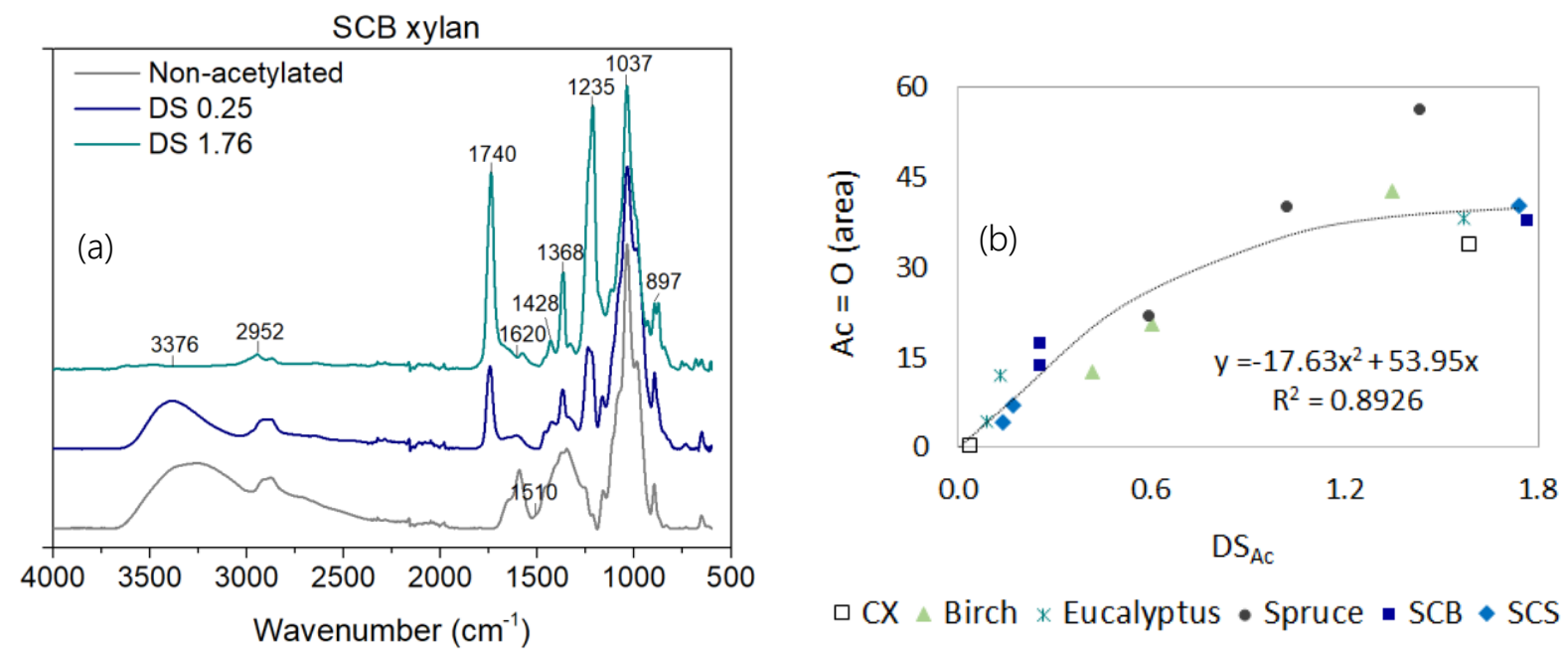

Figure 4. (a) FTIR spectra of non-acetylated ASX and acetylated xylans from sugarcane bagasse and (b) the area of the peak assigned for the carbonyl stretching $\left(\mathrm{A}_{\mathrm{C}}=\mathrm{O}\right)$ plotted against the degree of acetylation $\left(\mathrm{DS}_{\mathrm{Ac}}\right)$.

A positive correlation coefficient of was found between the area of the peak assigned for the carbonyl stretching $\left(\mathrm{A}_{\mathrm{C}}=\mathrm{O}\right)$ and the degree of acetylation $\left(\mathrm{DS}_{\mathrm{Ac}}\right)$ as shown in Figure $4 \mathrm{~b}$.

\subsubsection{Changes in polymer size and dispersion ability of xylan samples due to acetylation}

The solubility of CX and ASX samples (non-acetylated and acetylated) in water, dimethyl sulfoxide (DMSO) and chloroform $\left(\mathrm{CHCl}_{3}\right)$ was investigated (Table 3). The solubility in water and DMSO was 
investigated at both room temperature and $80^{\circ} \mathrm{C}$. In general, the behavior of the xylan samples in the different solvents was a dispersion rather than dissolution. The dissolution/dispersion of xylan samples was affected by both functional groups (i.e., acetyl groups) and the size of xylan chain and increased with heating.

Table 3. Solubility of CX and ASX (non-acetylated and acetylated) in water, DMSO and $\mathrm{CHCl}_{3}$. Numberaverage molar mass (Mn), weight-average molar mass (Mw) and dispersity (D) assessed using standard calibration and analyzed by SEC with the mobile phase $0.5 \% \mathrm{LiBr} / \mathrm{DMSO}$.

\begin{tabular}{|c|c|c|c|c|c|c|c|c|c|}
\hline \multirow[b]{2}{*}{ Sample } & \multirow[b]{2}{*}{$\mathrm{DS}_{\mathrm{Ac}} *$} & \multicolumn{5}{|c|}{ Solubility*** } & \multicolumn{3}{|c|}{ Standard calibration } \\
\hline & & $\begin{array}{c}\mathrm{H}_{2} \mathrm{O} \\
\left(\mathrm{RT}^{* *}\right)\end{array}$ & $\begin{array}{c}\mathrm{H}_{2} \mathrm{O} \\
\left(80^{\circ} \mathrm{C}\right)\end{array}$ & $\begin{array}{l}\text { DMSO } \\
\left(\mathrm{RT}^{* *}\right)\end{array}$ & $\begin{array}{l}\text { DMSO } \\
\left(80^{\circ} \mathrm{C}\right)\end{array}$ & $\begin{array}{l}\mathrm{CHCl}_{3} \\
\left(\mathrm{RT}^{* *}\right)\end{array}$ & $\mathrm{Mn}, \mathrm{kDa}$ & $\mathrm{Mw}, \mathrm{kDa}$ & $\mathrm{D}$ \\
\hline \multirow{2}{*}{$\begin{array}{l}\text { Commercial } \\
\text { Birch }\end{array}$} & 0.04 & - & ++ & - & ++ & + & $6.6 \pm 1.5$ & $17.7 \pm 0.4$ & $2.8 \pm 0.6$ \\
\hline & 1.59 & - & - & + & + & + & $4.4 \pm 0.1$ & $42.8 \pm 1.3$ & $9.7 \pm 0.1$ \\
\hline \multirow{3}{*}{ Birch } & Absent & - & ++ & - & + & + & $13.8 \pm 0.1$ & $23.7 \pm 0.2$ & $1.7 \pm 0.0$ \\
\hline & 0.42 & - & - & - & + & - & $14.0 \pm 0.7$ & $26.0 \pm 0.0$ & $1.9 \pm 0.1$ \\
\hline & 1.35 & - & - & - & + & - & $9.0 \pm 0.4$ & $35.4 \pm 1.0$ & $3.9 \pm 0.0$ \\
\hline \multirow{3}{*}{ Eucalyptus } & Absent & ++ & ++ & - & + & + & $6.4 \pm 0.1$ & $20.8 \pm 0.7$ & $3.3 \pm 0.2$ \\
\hline & 0.09 & + & + & - & + & - & $9.3 \pm 0.4$ & $24.6 \pm 0.2$ & $2.6 \pm 0.1$ \\
\hline & 1.57 & - & - & + & + & - & $9.3 \pm 0.1$ & $68.5 \pm 0.2$ & $7.4 \pm 0.1$ \\
\hline \multirow{3}{*}{ Spruce } & Absent & ++ & ++ & - & - & + & $5.3 \pm 0.0$ & $16.8 \pm 1.1$ & $3.2 \pm 0.2$ \\
\hline & 0.59 & - & + & + & + & + & $6.4 \pm 0.9$ & $30.8 \pm 0.6$ & $4.9 \pm 0.6$ \\
\hline & 1.43 & - & - & + & + & + & $21.1 \pm 2.7$ & $74.7 \pm 3.4$ & $3.6 \pm 0.6$ \\
\hline \multirow{3}{*}{$\begin{array}{l}\text { Sugarcane } \\
\text { bagasse }\end{array}$} & Absent & - & + & - & + & + & $18.8 \pm 0.0$ & $43.0 \pm 1.7$ & $2.3 \pm 0.1$ \\
\hline & 0.25 & - & - & - & + & - & $12.2 \pm 1.3$ & $44.7 \pm 0.5$ & $3.7 \pm 0.3$ \\
\hline & 1.76 & - & - & - & + & + & $8.1 \pm 0.5$ & $49.3 \pm 0.2$ & $6.1 \pm 0.4$ \\
\hline \multirow{3}{*}{$\begin{array}{l}\text { Sugarcane } \\
\text { straw }\end{array}$} & Absent & - & + & - & + & + & $13.2 \pm 0.8$ & $47.0 \pm 2.9$ & $3.6 \pm 0.0$ \\
\hline & 0.14 & - & + & + & + & - & $14.3 \pm 1.1$ & $44.1 \pm 0.2$ & $3.1 \pm 0.3$ \\
\hline & 1.74 & - & - & - & + & + & $12.5 \pm 0.1$ & $68.0 \pm 0.7$ & $5.5 \pm 0.0$ \\
\hline
\end{tabular}

*[Degree of substitution with acetyl groups in xylan structure].

$* *[$ Room temperature $]$.

$* * *[++$ soluble/well dispersed, + partially soluble or partially dispersed and - hardly soluble or insoluble $]$.

The results indicated that the xylan extracted through the $\mathrm{NaClO}_{2} / \mathrm{KOH}$ process had quite an intact structure. This conclusion was supported by the slightly higher molecular weights obtained in the present study compared to those in the literature (Escalante et al., 2012; Gröndahl, Teleman, \& Gatenholm, 2003; Morais de Carvalho et al., 2017) (Table 3). Other evidence was the similar molecular weights values for CX and ASX from birch, although slightly higher for the ASX sample. The lower molecular weights of methylglucuronoxylan (birch and eucalyptus) and arabinoglucuronoxylan (spruce), than that of the glucuronoarabinoxylan (bagasse and straw), increased their dissolution/dispersion in water (Table 3). A 
reduction in their solubility in water was observed due to acetylation, even when heating was applied.

Unlike the observations of Gröndahl, Teleman, \& Gatenholm (2003), the average molecular weight of the xylan increased with acetylation as result of the substitution of hydroxyl groups by acetyl groups, which indicates that the acetylation led to negligible degradation of the xylan chains. The increase in average molecular weight, cannot, however, be explained only by the substitution of hydroxyl groups by a heavier group. This substitution has some effect, but the fact that the acetyl substitution affected the hydrodynamic volume may be more important. Evidence of changes in the hydrodynamic volume of the xylan samples was that the molecular weight distribution trended to be broader after acetylation, containing components with lower and, especially, higher molecular weights than the original xylans (Fig. 5 and Fig. S2 in Supplementary Data). In the original samples, these xylan components probably formed aggregates, which limited their assessment by SEC, and consequently reduced the variability of values used for the estimation of the average molecular weight. The presence of components with a higher molecular weight (right part of the curves) significantly increased the average molecular weight of the samples, even though the molecular weight distribution had not notably changed (Fig. 5 and Fig. S2 in Supplementary Data).

The molecular weights of acetylated xylan were in a range similar to that reported elsewhere (Evtuguin, Tomás, Silva, \& Neto, 2003; Morais de Carvalho et al., 2017; Shatalov, Evtuguin, \& Neto, 1999). The results showed the presence of different populations of xylan in the acetylated samples, probably due to a random acetylation pattern (Fig. 5 and Fig. S2 in Supplementary Data). Although the components with higher or lower molecular weights represented only a small fraction of the xylan material, they affected average molar mass, and resulted in an increased dispersity of the xylan structures compared to those of the non-acetylated material. Except for spruce xylan, the functionalization of the xylan samples did not affect the solubility in DMSO, although a positive effect of heating was observed. The pour solubility of nonacetylated spruce xylan, in DMSO probably contributed to the low molecular weight obtained by SEC analysis. When the degree of acetylation of xylan was increased the solubility of populations with low and, especially, high molecular weights increased, as confirmed by the results presented in Table 3, Figure 5 and Supplementary Data (Figure S2). 
Xylan samples formed a colloidal dispersion in chloroform, but a higher degree of acetylation formation of aggregates.

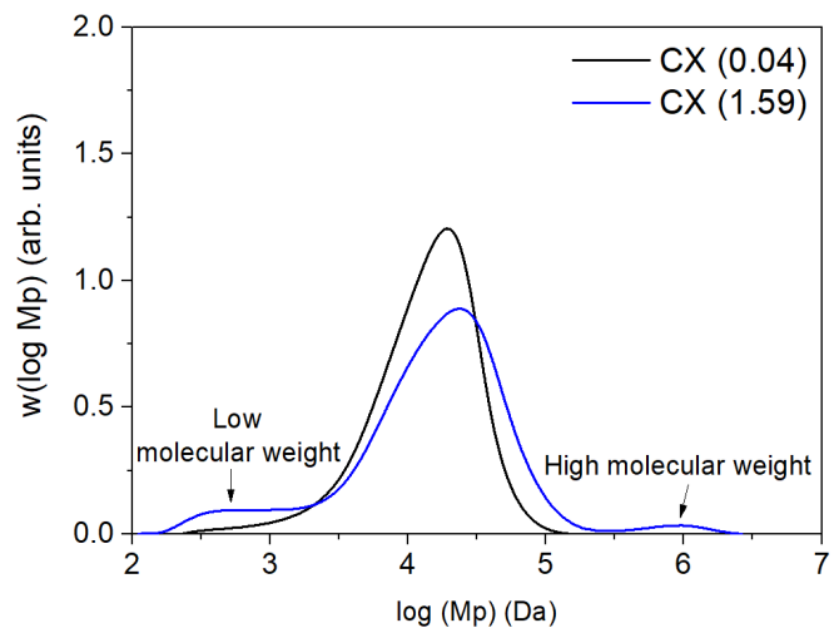

Figure 5. Molecular weight distribution of non-acetylated and acetylated xylan from CX. The molecular weight distributions of non-acetylated ASX and of acetylated xylans from birch, eucalyptus, spruce, sugarcane bagasse and straw are shown in the Supplementary Data (Fig. S2).

\subsubsection{Controlled acetylation to greater thermal stability of the xylan samples regardless of their origin}

The thermal properties of the xylan samples were studied by TGA and DSC. The main thermogravimetric results are shown in Table 4, and the TGA thermograms for SCS samples are presented in Fig. 6a. The TGA thermograms for the other xylan samples were similar to that of the SCS sample and they are presented in the Supplementary Data (Fig. S3). The thermograms showed that the xylan samples underwent two different decomposition processes during heating $\left(25-600^{\circ} \mathrm{C}\right)$, the first being a loss of moisture $(0.2-7.7 \%)$ at the beginning of the heating $\left(25-100^{\circ} \mathrm{C}\right)$, where the acetylation caused a reduction in the amount of hydroxyl groups in xylan samples due to their substitution by acetyl groups and a reduction in the moisture content. 

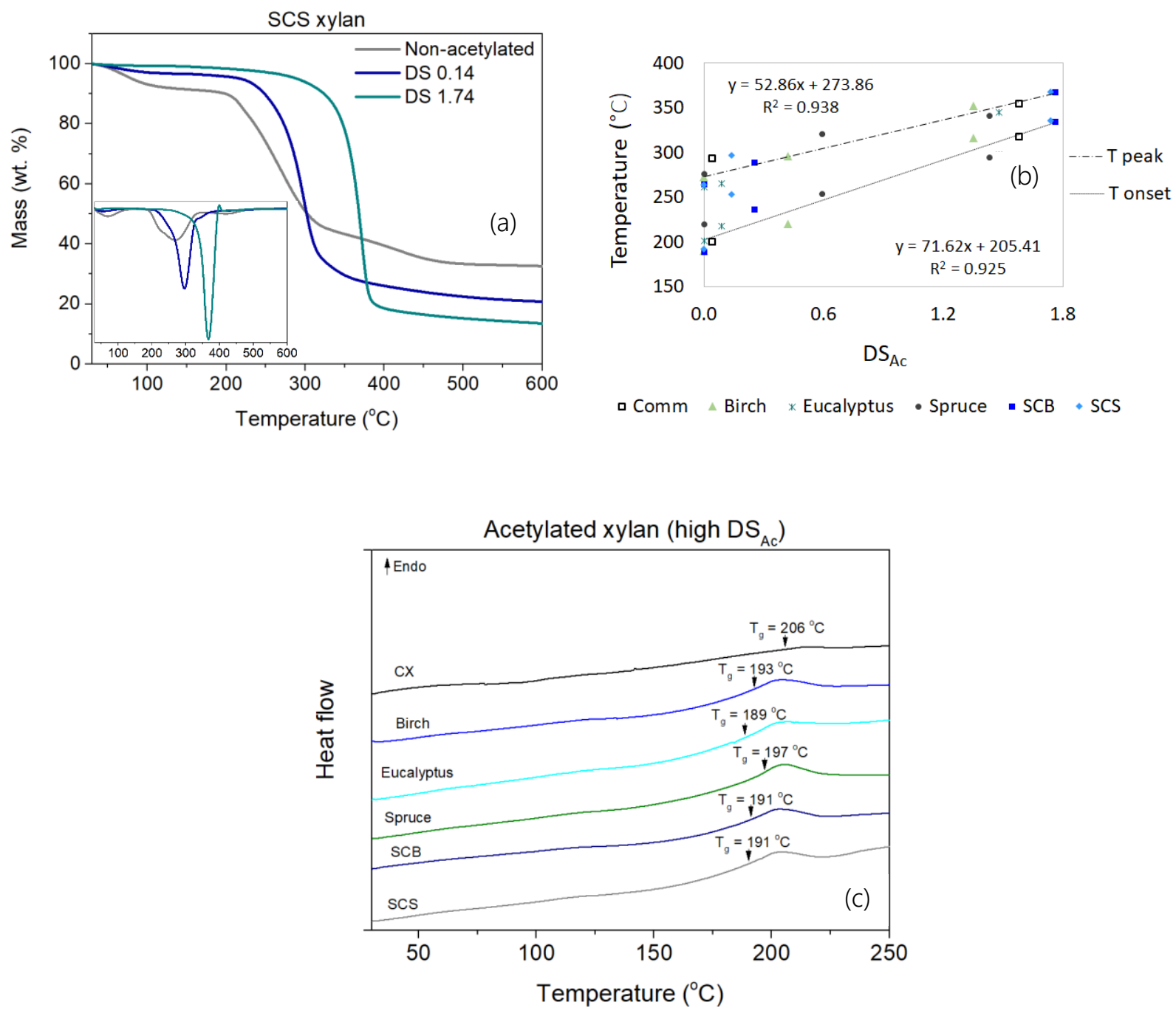

Figure 6. (a) Thermal decomposition and derivative thermogravimetric curves of non-acetylated ASX and acetylated xylans from sugarcane straw and (b) relationship between thermal properties and degree of acetylation (DS $\mathrm{Ac}_{\mathrm{Ac}}$ ) and (c) differential scanning calorimetry (DSC) (second heating scan) of xylan samples acetylated at high degrees.

The second process $\left(150-450^{\circ} \mathrm{C}\right)$ was the thermal decomposition of the xylan itself, with a mass loss of 49.9-84.3\% (on dry basis). The derivative thermogravimetric curves (thermograms shown in the left corner in Fig. 6a) show the temperature at which the maximum rate of decomposition occurred. The thermal stability of xylan was defined by the temperature at the onset of degradation (T onset). Acetylation increased the thermal stability of the xylans: an increase by $16.6-60.6^{\circ} \mathrm{C}$ was observed for the various biomass xylans 
compared with the non-acetylated xylans. The effect of acetylation became more evident when the nonacetylated xylans were compared with those acetylated to a high degree, the thermal stability increased by $69.8-145.0^{\circ} \mathrm{C}$. These results can be explained by MeGlcA hydrolysis, which is speeded when the amount of water in the xylan samples is increased (Gröndahl, Teleman, \& Gatenholm, 2003). The lower water content of the acetylated xylans (Table 4) was less efficient in catalyzing the MeGlcA hydrolysis, resulting in a more thermally stable xylan. The increase in thermal stability also coincided with the increase in molecular weight of the samples.

Table 4. Derivative thermogravimetric (DTG), residues content and glass transition temperature $\left(\mathrm{T}_{\mathrm{g}}\right)$ of xylan samples

\begin{tabular}{|c|c|c|c|c|c|c|c|c|}
\hline \multirow[b]{2}{*}{ Sample } & \multirow{2}{*}{$\mathrm{DS}_{\mathrm{Ac}} *$} & \multicolumn{2}{|c|}{$[25-100]^{\circ} \mathrm{C}$} & \multicolumn{3}{|c|}{$[150-450]^{\circ} \mathrm{C}$} & \multirow{2}{*}{$\begin{array}{c}\text { Residues at } \\
600^{\circ} \mathrm{C}, \\
\text { wt. } * * \%\end{array}$} & \multirow[b]{2}{*}{$\mathrm{Tg},{ }^{\circ} \mathrm{C}$} \\
\hline & & wt. $\%$ & $\mathrm{~T}$ peak, ${ }^{\circ} \mathrm{C}$ & $\mathrm{T}$ onset, ${ }^{\circ} \mathrm{C}$ & wt. $* * \%$ & $\mathrm{~T}$ peak, ${ }^{\circ} \mathrm{C}$ & & \\
\hline \multirow{2}{*}{$\begin{array}{c}\text { Commercial } \\
\text { Birch }\end{array}$} & 0.04 & $4.2 \pm 0.5$ & $77.9 \pm 0.5$ & $200.6 \pm 0.4$ & $60.3 \pm 0.5$ & $294.1 \pm 0.1$ & $31.5 \pm 0.1$ & $131.7 \pm 0.8$ \\
\hline & 1.59 & $0.6 \pm 0.1$ & $43.6 \pm 0.6$ & $318.5 \pm 1.3$ & $82.6 \pm 1.3$ & $355.5 \pm 0.4$ & $11.2 \pm 1.4$ & $206.3 \pm 0.9$ \\
\hline \multirow{3}{*}{ Birch } & Absent & $7.7 \pm 0.0$ & $70.0 \pm 0.5$ & $188.9 \pm 0.1$ & $49.9 \pm 0.3$ & $272.2 \pm 0.7$ & $32.8 \pm 0.6$ & $129.9 \pm 1.0$ \\
\hline & 0.42 & $2.6 \pm 0.0$ & $51.3 \pm 2.5$ & $220.0 \pm 0.1$ & $71.1 \pm 2.4$ & $295.5 \pm 1.0$ & $21.4 \pm 2.5$ & $127.9 \pm 2.3$ \\
\hline & 1.35 & $1.2 \pm 0.1$ & $43.7 \pm 0.4$ & $316.4 \pm 0.6$ & $76.2 \pm 1.0$ & $352.4 \pm 0.0$ & $17.0 \pm 0.9$ & $192.8 \pm 0.4$ \\
\hline \multirow{3}{*}{ Eucalyptus } & Absent & $5.4 \pm 0.1$ & $73.4 \pm 2.1$ & $200.8 \pm 0.3$ & $60.4 \pm 0.1$ & $261.6 \pm 1.2$ & $33.1 \pm 0.5$ & $121.6 \pm 2.0$ \\
\hline & 0.09 & $3.5 \pm 0.6$ & $45.8 \pm 2.0$ & $217.4 \pm 0.6$ & $59.8 \pm 2.0$ & $265.0 \pm 0.3$ & $31.2 \pm 5.4$ & $124.6 \pm 2.5$ \\
\hline & 1.57 & $1.2 \pm 0.2$ & $43.0 \pm 0.1$ & $297.1 \pm 0.2$ & $80.1 \pm 3.3$ & $344.5 \pm 0.0$ & $14.8 \pm 4.1$ & $188.7 \pm 1.7$ \\
\hline \multirow{3}{*}{ Spruce } & Absent & $6.0 \pm 0.2$ & $65.1 \pm 0.3$ & $220.0 \pm 1.0$ & $63.1 \pm 2.6$ & $276.2 \pm 0.1$ & $32.1 \pm 2.3$ & $120.8 \pm 0.4$ \\
\hline & 0.59 & $2.0 \pm 0.1$ & $44.4 \pm 0.0$ & $253.0 \pm 0.1$ & $69.5 \pm 3.9$ & $321.2 \pm 1.2$ & $20.5 \pm 4.2$ & $127.9 \pm 0.5$ \\
\hline & 1.43 & $0.2 \pm 0.1$ & $44.1 \pm 0.0$ & $294.8 \pm 0.4$ & $71.7 \pm 1.0$ & $341.8 \pm 1.6$ & $20.4 \pm 2.4$ & $196.7 \pm 0.9$ \\
\hline \multirow{3}{*}{$\begin{array}{c}\text { Sugarcane } \\
\text { bagasse }\end{array}$} & Absent & $4.9 \pm 0.1$ & $77.1 \pm 1.3$ & $189.5 \pm 0.4$ & $62.5 \pm 1.2$ & $265.1 \pm 4.1$ & $33.3 \pm 1.3$ & $121.5 \pm 0.1$ \\
\hline & 0.25 & $2.9 \pm 0.2$ & $76.1 \pm 1.0$ & $236.8 \pm 3.8$ & $70.4 \pm 1.9$ & $289.3 \pm 1.7$ & $22.8 \pm 1.4$ & $123.8 \pm 0.3$ \\
\hline & 1.76 & $0.6 \pm 0.0$ & $42.3 \pm 0.1$ & $334.5 \pm 0.5$ & $84.3 \pm 3.2$ & $367.6 \pm 0.2$ & $11.7 \pm 3.5$ & $190.5 \pm 1.3$ \\
\hline \multirow{3}{*}{$\begin{array}{l}\text { Sugarcane } \\
\text { straw }\end{array}$} & Absent & $4.5 \pm 0.1$ & $80.4 \pm 1.7$ & $192.3 \pm 0.6$ & $59.5 \pm 1.2$ & $263.7 \pm 3.8$ & $34.5 \pm 1.5$ & $125.2 \pm 0.8$ \\
\hline & 0.14 & $3.2 \pm 0.1$ & $55.5 \pm 1.1$ & $252.9 \pm 0.4$ & $68.4 \pm 2.1$ & $297.2 \pm 1.8$ & $22.8 \pm 1.7$ & $128.1 \pm 0.1$ \\
\hline & 1.74 & $0.6 \pm 0.1$ & $43.1 \pm 0.2$ & $335.5 \pm 1.1$ & $82.4 \pm 0.0$ & $367.4 \pm 0.3$ & $13.7 \pm 0.1$ & $190.6 \pm 1.1$ \\
\hline
\end{tabular}

*[Degree of substitution with acetyl groups in xylan structure].

$* *$ [On dry basis].

The temperature of the maximum rate of decomposition was given by the temperature at the peak of decomposition (T peak). The T peak of the xylan samples increased with increasing acetylation, but the decomposition was more rapid. The difference between the $\mathrm{T}$ peak and the $\mathrm{T}$ onset $\left(\Delta \mathrm{T}_{\mathrm{T} \text { peak }-\mathrm{T} \text { onset }}\right)$, which was in the range of $56-82.4^{\circ} \mathrm{C}$ for the non-acetylated xylans, were, decreased to $44.3-75.5^{\circ} \mathrm{C}$ for xylans 
acetylated to a low degree and to $31.9-49.5^{\circ} \mathrm{C}$ for xylans acetylated to a high degree (Table 4 and Fig. 6a).

A small peak was observed at $420^{\circ} \mathrm{C}$ in the derivative thermograms of non-acetylated xylan samples (Fig. 6a), indicating the presence of small amount of residual lignin in the xylan samples (Egüés et al., 2014).

The amount of residue (char + ash) recovered at $600^{\circ} \mathrm{C}$ decreased with increasing degree of acetylation. The reduction in residue at $600^{\circ} \mathrm{C}$ varied between 48.3 and $64.7 \%$ comparing xylans acetylated to a high degree with their non-acetylated counterparts.

Positive relationship was found between $\mathrm{T}$ onset and $\mathrm{DS}_{\mathrm{Ac}}$ and between $\mathrm{T}$ peak and $\mathrm{DS}_{\mathrm{Ac}}$ as shown in Figure $6 \mathrm{~b}$, but the thermal stability of xylan samples, did not show a clear correlation with the molecular weight indicating that the functionalization affected the thermal stability of samples more than the size of the xylan chain regardless of xylan type.

The glass transition temperature $\left(\mathrm{T}_{\mathrm{g}}\right)$ of xylan samples was determined from DSC spectra in the second heating scan after normalization with respect to by sample weight. The results are presented in Table 4 and Figure 6c. Only spectra for xylan acetylated to a high degree is presented in Figure 6c. Results for non-acetylated xylan and xylan acetylated to a low degree are presented in the Supplementary Data (Fig. S4). The acetylation increased the $\mathrm{T}_{\mathrm{g}}$ of the xylan samples. $\mathrm{A}_{\mathrm{g}}$ peak between $189-206^{\circ} \mathrm{C}$ was observed for all the xylans acetylated to a high degree $\left(\mathrm{DS}_{\mathrm{Ac}}\right.$ 1.35-1.76). For the non-acetylated xylan and for xylan samples acetylated to a low degree $\left(\mathrm{DS}_{\mathrm{Ac}} 0.09-0.59\right)$, a discreet $\mathrm{T}_{\mathrm{g}}$ peak was identified between $121-132^{\circ} \mathrm{C}$. Gröndahl, Teleman, \& Gatenholm (2003) did not observe any $\mathrm{T}_{\mathrm{g}}$ for aspen glucuronoxylan non-acetylated and with $\mathrm{DS}_{\mathrm{Ac}}=0.6$, but reported a clear $\mathrm{T}_{\mathrm{g}}$ (between $160-200^{\circ} \mathrm{C}$ ) for glucuronoxylan acetylated to a high degree $\left(\mathrm{DS}_{\mathrm{Ac}}=1.2\right)$. Only a vague $\mathrm{T}_{\mathrm{g}}$ has been reported for fully acetylated sample (DS $\mathrm{Ac}_{\mathrm{Ac}}$ around 1.9). These authors attributed the results to the presence of acetyl groups on xylan chains preventing the formation of hydrogen bonds, which results in a greater mobility of the xylan chain. The xylan decomposition is an exothermic process (Yang, Yan, Chen, Lee, \& Zhen, 2007). According to Ball, McIntostosh, \& Brindley (2004), the exothermic nature of this reaction is due to char formation. This statement was confirmed for our samples, since a certain amount of char was observed in the aluminum crucible after DSC analysis, 
especially in the case of the non-acetylated samples (Fig. S5 - Supplementary Data).

\section{Conclusions}

Alkaline soluble xylans (ASX) were isolated with high yields and satisfactory purity from birch, eucalyptus, spruce, sugarcane bagasse and sugarcane straw. The presence of methylglucuronoxylan in birch $(23.7 \mathrm{kDa})$ and eucalyptus $(20.8 \mathrm{kDa})$, of arabinoglucuronoxylan in spruce $(16.8 \mathrm{kDa})$ and of glucuronoarabinoxylan in sugarcane bagasse $(43.0 \mathrm{kDa})$ and straw $(47.0 \mathrm{kDa})$ was confirmed. The higherpurity CX sample (96\%) and the four purification steps applied to spruce xylan led to the greater reactivity of these samples during acetylation. Xylan samples acetylated to low (0.1-0.6) and high (1.4-1.8) degrees of acetylation had a higher molecular weight than their counterparts. A substantial improvement in thermal stability of xylan samples was observed as a result of the acetylation, regardless of molecular weight or xylan type. An increase of $17-61^{\circ} \mathrm{C}$ and $70-145^{\circ} \mathrm{C}$ in the thermal stability of xylan was observed at low and high degrees of acetylation, respectively. The $\mathrm{T}_{\mathrm{g}}$ temperature was in the range of $121-132^{\circ} \mathrm{C}$ for the samples non-acetylated and acetylated at low degree of acetylation (0.1-0.6) and increased to the range of $188-206^{\circ} \mathrm{C}$ in samples acetylated at high degree of acetylation (1.4-1.8). Acetylation proved to be an efficient method of increasing the thermal stability of the xylan. This opens new avenues for the utilization of acetylated xylan from different biomass resources for use as thermoplastics and packaging.

\section{Acknowledgements}

Danila Carvalho thanks the Wood and Pulping Chemistry Research Network (WPCRN) project for their financial support. Jennie Berglund acknowledges the Knut and Alice Wallenberg foundation for funding through the Wallenberg Wood Science Center at the Royal Institute of Technology (KTH).

\section{References}

Appeldoorn, M. M., Kabel, M. A., Van Eylen, D., Gruppen, H., \& Schols, H. A. (2010). Characterization of oligomeric xylan structures from corn fiber resistant to pretreatment and simultaneous saccharification and 
fermentation. Journal of Agricultural and Food Chemistry, 58, 11294-11301.

Ball, R., McInstosh, A. C., \& Brindley, J. (2004). Feedback processes in cellulose thermal decomposition implications for fire-retarding strategies and treatments. Combust. Theory Modelling, 8, 281-291.

Belmokaddem, F-Z., Pinel, C., Huber, P., Petit-Conil, M., \& Da Silva Perez, D. (2011). Green synthesis of xylan hemicellulose esters. Carbohydrate Research, 346(18), 2896-2904.

Bertaud, F., \& Holmbom, B. (2004). Chemical composition of earlywood and latewood in Norway spruce heartwood, sapwood and transition zone wood. Wood Science and Technology, 38, 245-256.

Bertaud, F., Sundberg, A., \& Holmbom, B. (2002). Evaluation of acid methanolysis for analysis of wood hemicelluloses and pectins. Carbohydrate Polymers, 48, 319-324.

Bi, R., Berglund, J., Vilaplana, F., McKee, L. S., \& Henriksson, G. (2016). The degree of acetylation affects the microbial degradability of mannans. Polymer Degradation and Stability, 133, 36-46.

Bian J., Peng, F., Xu, F., Sun, R-C., \& Kennedy, J. F. (2010). Fractional isolation and structural characterization of hemicelluloses from Caragana korshinskii. Carbohydrate Polymers, 80, 753-760.

Brandt, A., Gräsvik, J., Hallett, J. P., \& Welton, T. (2013). Deconstruction of lignocellulosic biomass with ionic liquids. Green Chemistry, 15(3), 550-583.

Carvalho, D. M. de. (2015). Study on the structure and properties of xylan extracted from eucalyptus, sugarcane bagasse and sugarcane straw. Royal Institute of Technology, pp. 53 (Licentiate thesis).

Carvalho, D. M. de, Sevastyanova, O., Penna, L. S., Silva, B. P. da, Lindström, M. E., \& Colodette, J. L. (2015). Assessment of chemical transformations in eucalyptus, sugarcane bagasse and straw during hydrothermal, dilute acid, and alkaline pretreatments. Industrial Crops and Products, 73, 118-126.

Chaikumpollert, O., Methacanon, P., \& Suchiva, K. (2004). Structural elucidation of hemicelluloses from Vetiver grass. Carbohydrate Polymers, 57, 191-196.

Chang, V. S., \& Holtzapple, M. T. (2000). Fundamental factors affecting biomass enzymatic reactivity. Applied Biochemistry and Biotechnology, 84-86, 5-37.

Conab. (2015). Companhia nacional de abastecimento. (http://www.conab.gov.br/OlalaCMS/uploads/arquivos/16_02_23_17_34_53_boletim_cana_portugues_- 
_3o_lev_-_15-16.pdf), accessed 9 April 2018.

Drobniak, A., \& Mastalerz, M. (2006). Chemical evolution of Miocene wood: Example from the Belchatow brown coal deposit, central Poland. International Journal of Coal Geology, 66, 157-178.

Ebringerová, A., Hromádková, Z., \& Heinze, T. (2005). Hemicelluloses. Advances in Polymer Science, 186, $1-67$.

Egües, I., Stepan, A. M., Eceiza, A., Toriz, G., Gatenholm, P., \& Labidi, J. (2014). Corncob arabinoxylan for new materials. Carbohydrate Polymers, 102, 12-20.

Escalante, A., Gonçalves, A., Bodin, A., Stepan, A., Sandström, C., Toriz, G., \& Gatenholm, P. (2012). Flexible oxygen barrier films from spruce xylan. Carbohydrate Polymers, 87, 2381-2387.

Evtuguin, D. V., Tomás, J. L., Silva, A. M. S., \& Neto, P. C. (2003). Characterization of an acetylated heteroxylan from Eucalyptus globulus Labill. Carbohydrate Research, 338, 597-604.

Gonzáles-García, S., Moreira, M. T., Feijoo, G., \& Murphy, R. J., (2012). Comparative life cycle assessment of ethanol production from fast-growing wood crops (black locust, eucalyptus and poplar). Biomass Bioenergy, 39, 378-388.

Gröndahl, M., Teleman, A. \& Gatenholm, P. (2003). Effect of acetylation on the material properties of glucuronoxylan from aspen wood. Carbohydrates Polymers, 53, 359-366.

Gupta, S., Madan, R. N., \& Bansal, M. C. (1987). Chemical composition of Pinus caribaea hemicellulose. Tappi Journal, 70(8), 113-114.

Hansson, J-Å., \& Hartler, N. (1968). Alkaline degradation of xylans from birch and pine. Svensk Papperstidning, 71 (9), 358-365.

Kačuráková, M., Belton, P. S., Wilson, R.H., Hirsch, J., \& Ebringerová, A. (1998). Hydration properties of xylan-type structures: an FTIR study of xylooligosaccharides. Journal of Science Food and Agriculture, $77,38-44$.

Lu, F., \& Ralph, J. (2003). Non-degradative dissolution and acetylation of ball-milled plant cell walls: highresolution solution-state NMR. The Plant Journal, 35, 535-544.

Magaton, A. da S. (2008). Comportamento e caracterização de xilanas durante a polpação kraft de 
eucalipto. Federal University of Minas Gerais, pp. 259 (PhD thesis).

Martínez-Abad, A., Giummarella, N., Lawoko, M., \& Vilaplana, F. (2018). Differences in extractability under subcritical water reveal interconnected hemicellulose and lignin recalcitrance in birch hardwoods. Green Chemistry, 20, 2534-2546.

Martínez-Abad, A., Berglund, B., Toriz, G., Gatenholm, P., Henriksson, G., Lindström, M., Wohlert, J., \& Vilaplana, F. (2017). Regular Motifs in Xylan Modulate Molecular Flexibility and Interactions with Cellulose Surfaces. Plant Physiology, 175, 1579-1592.

McKee, L. S., Sunner, H., Anasontzis, G. E., Toriz, G., Gatenholm, P., Bulone, V., Vilaplana, F., \& Olsson, L. (2016). A GH115 $\alpha$-glucuronidase from Schizophyllum commune contributes to the synergistic enzymatic deconstruction of softwood glucuronoarabinoxylan. Biotechnology for Biofuels, 9:2.

Morais de Carvalho, D., Marchand, C., Berglund, J., Lindström, M. E., Vilaplana, F., \& Sevastyanova, O. (2019). Impact of birch xylan composition and structure on film formation and properties. Holzforschung, DOI: $10.1515 / \mathrm{hf}-2018-0224$.

Morais de Carvalho, D., Martínez-Abad, A., Evtuguin, D. V., Colodette, J. L., Lindström, M. E., Vilaplana, F., \& Sevastyanova, O. (2017). Isolation and characterization of acetylated glucuronoarabinoxylan from sugarcane bagasse and straw. Carbohydrate Polymers, 156, 223-234.

Shatalov, A. A., Evtuguin, D. V., \& Neto, P. C. (1999). (2-O- $\beta-D-G a l a c t o p y r a n o s y l-4-O-m e t h y l-\beta-D-$ glucurono)-D-xylan from Eucalyptus globulus labill. Carbohydrate Research, 320, 93-99.

Sun, J. X., Sun, X. F., Sun, R. C., Su, Y. Q. (2004). Fractional extraction and structural characterization of sugarcane bagasse hemicelluloses. Carbohydrate Polymers, 56, 195-204.

TAPPI. (2011). Technical association of the pulp and paper industry. pp. 2011. Atlanta, GA: Standard Test Methods.

Teleman, A., Tenkanen, M., Jacobs, A., \& Dahlman, O. (2002). Characterization of O-acetyl-(4-Omethylglucurono)xylan isolated from birch and beech. Carbohydrate Research, 337, 373-377.

Timell, T. E. (1961). Isolation of galactoglucomannans from wood of gymnosperms. Tappi Journal, 44(2), 88-96. 
Xu, C, Leppären, A-S., Eklund, P., Holmlund, P., Sjöholm, R., Sundberg, K., \& Willför, S. (2010) Acetylation and characterization of spruce (Picea abies) galactoglucomannans. Carbohydrate Research, $345,810-816$.

Yang, H., Yan, R., Chen, H., Lee, D. H., \& Zhen, C. (2007). Characteristics of hemicellulose, cellulose and lignin pyrolysis. Fuel, 86, 1781-1788.

Zhang, A. P., Liu, C. F., Sun, R. C., Xie, J., \& Chen, X. Y. (2012). Homogeneous acylation of eucalyptus wood at room temperature in dimethyl sulfoxide/N-methylimidazole. Bioresource Technology, 125, 328331.

Zhang, X., Zhang, A., Liu, C. \& Ren, J. (2016). Per-O-acylation of xylan at room temperature in dimethylsulfoxide/N-methylimidazole. Cellulose, 23, 2863-2876. 
Supplementary Data

Commercial birch xylan
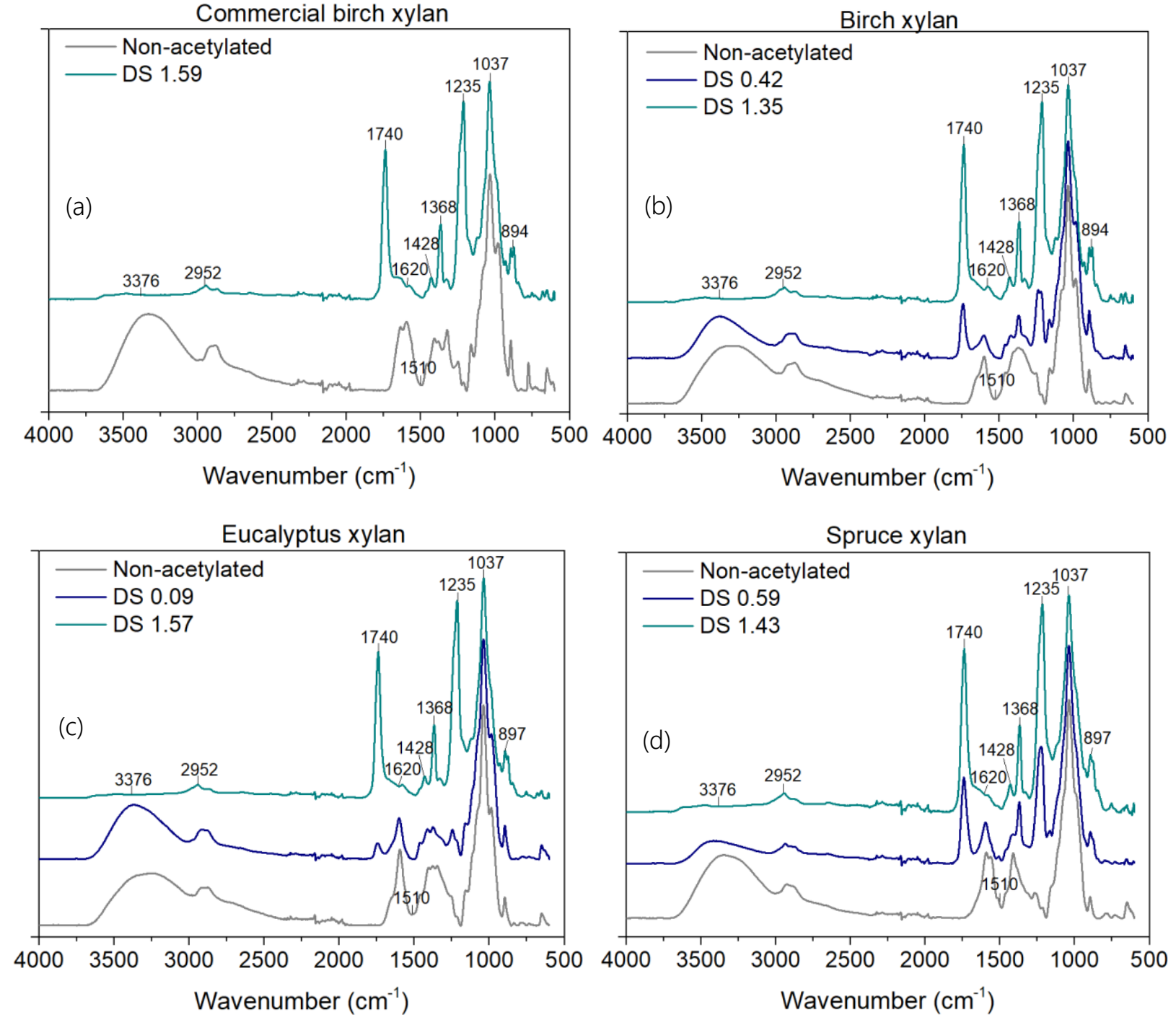

SCS xylan

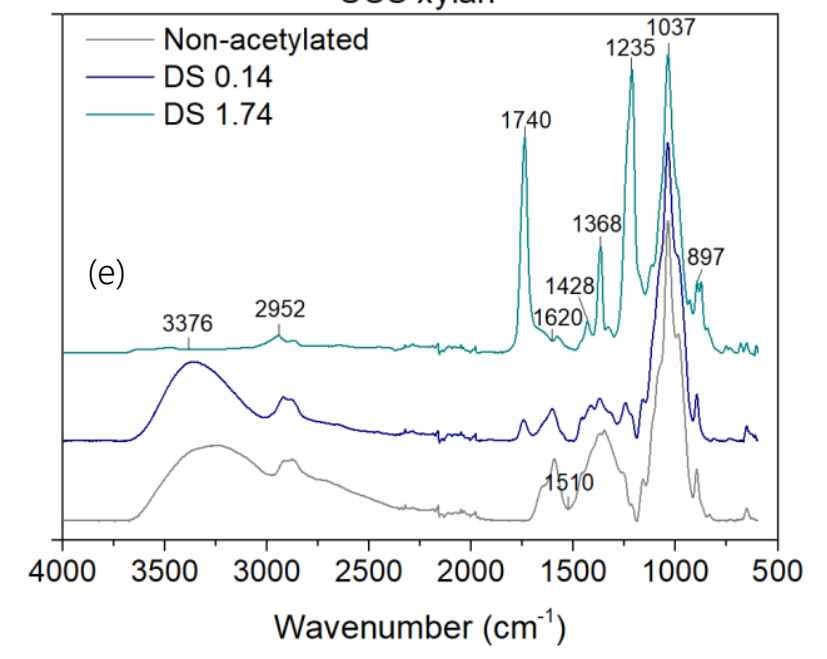


Figure S1. (a) FTIR spectra of non-acetylated ASX and acetylated xylans from commercial birch, (b) birch, (c) eucalyptus, (d) spruce and (e) sugarcane straw.
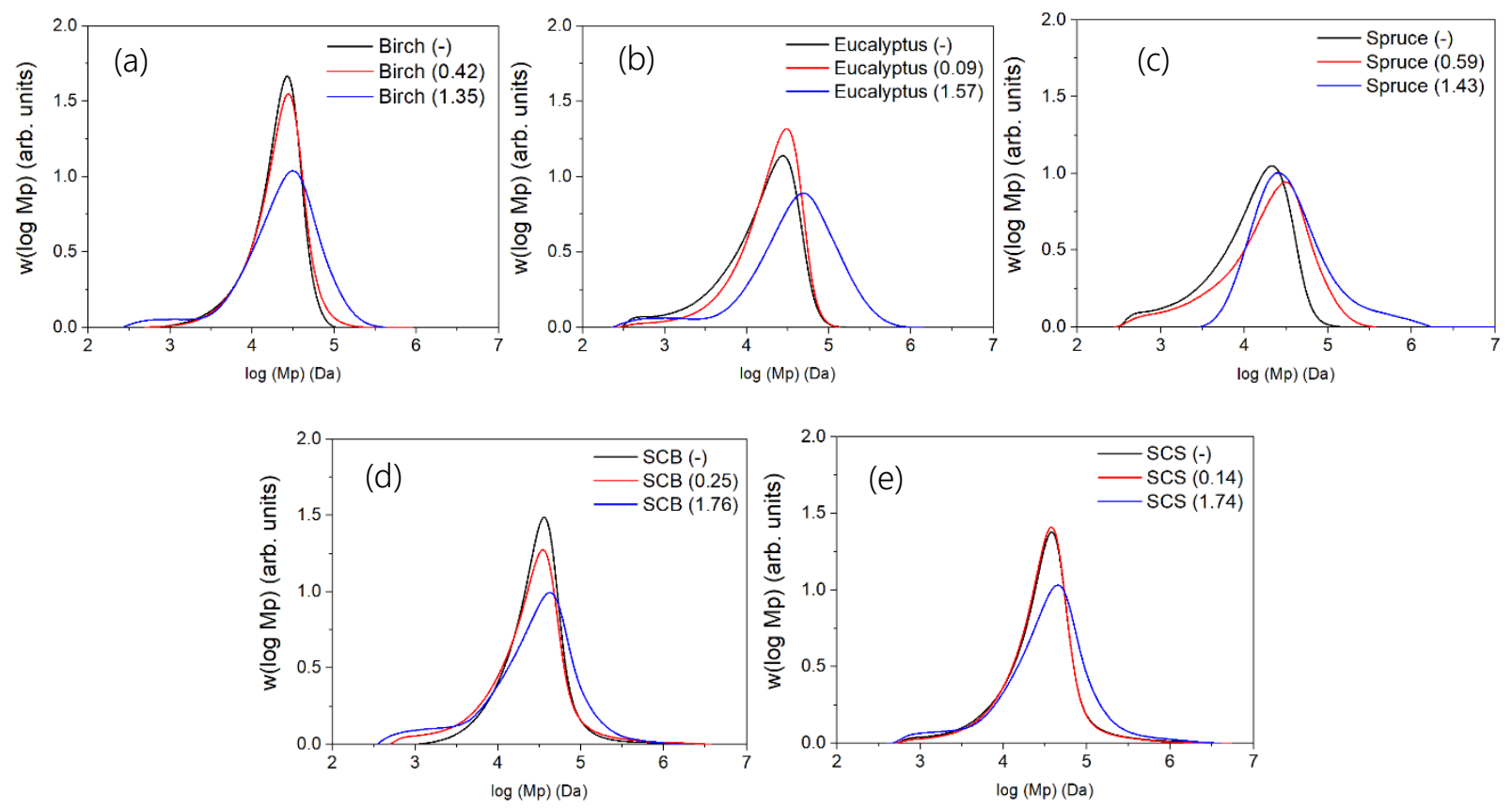

Figure S2. Molecular weight distribution of non-acetylated ASX and acetylated xylans from (a) birch, (b) eucalyptus, (c) spruce, (d) sugarcane bagasse and (e) sugarcane straw. 

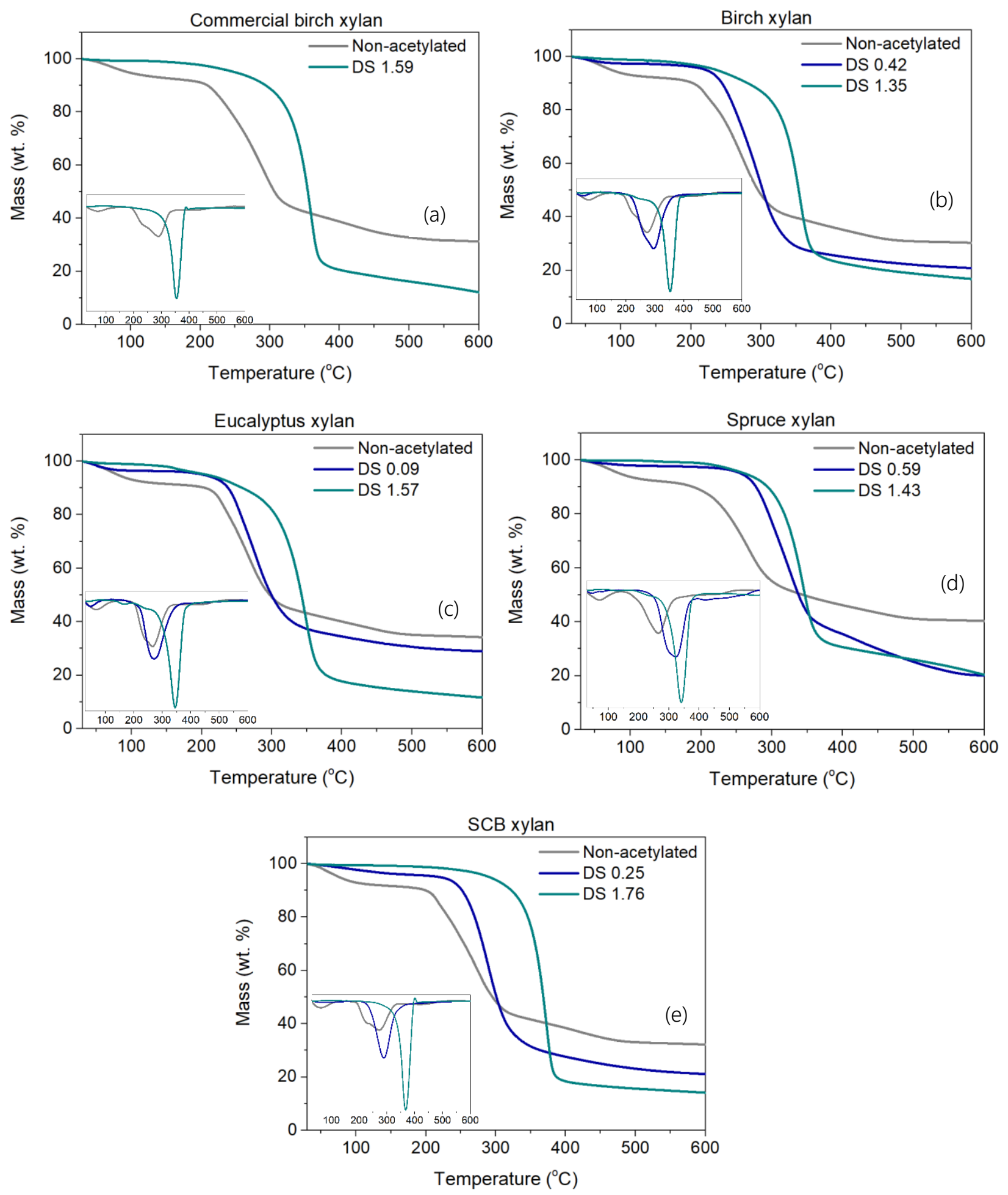

Figure S3. (a) Thermal decomposition and derivative thermogravimetric curves of non-acetylated ASX and acetylated xylans from commercial birch, (b) birch, (c) eucalyptus, (d) spruce and (e) sugarcane bagasse. 

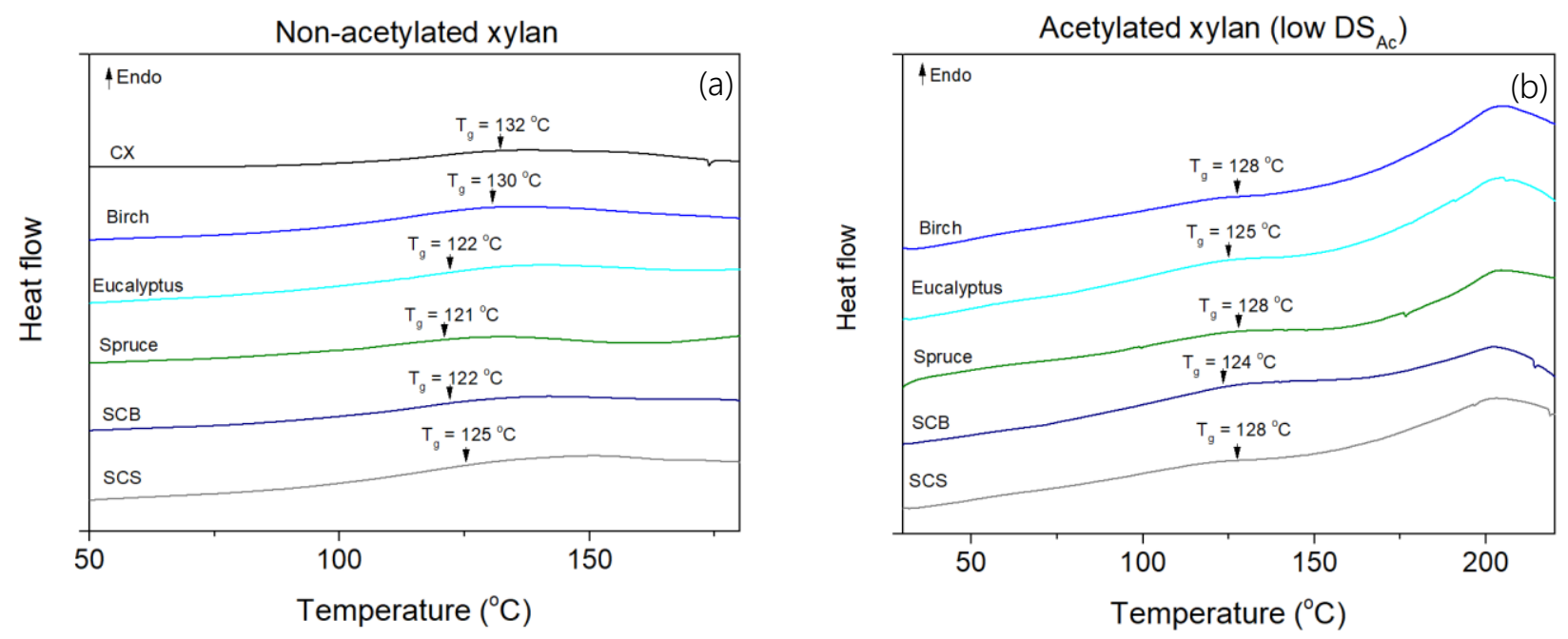

Figure S4. Differential scanning calorimetry (DSC) (second heating scan) of (a) non-acetylated xylan samples and (b) xylan samples acetylated at low degrees.

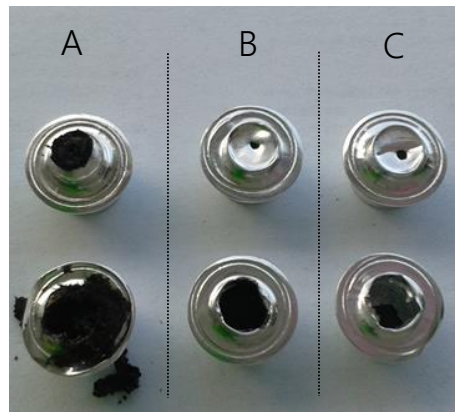

Figure S5. Char formation during DSC analysis for (a) non-acetylated xylan sample and xylan samples acetylated at (b) low and (c) high degrees. 